A s i a n J o u r n a l of

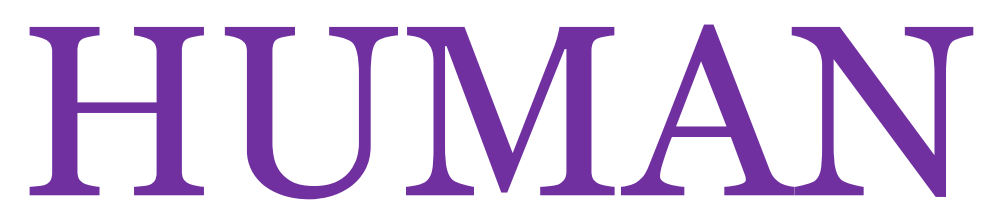

Printed 2020.1030 ISSN2188-059X

Published by Asian Society of Human Services

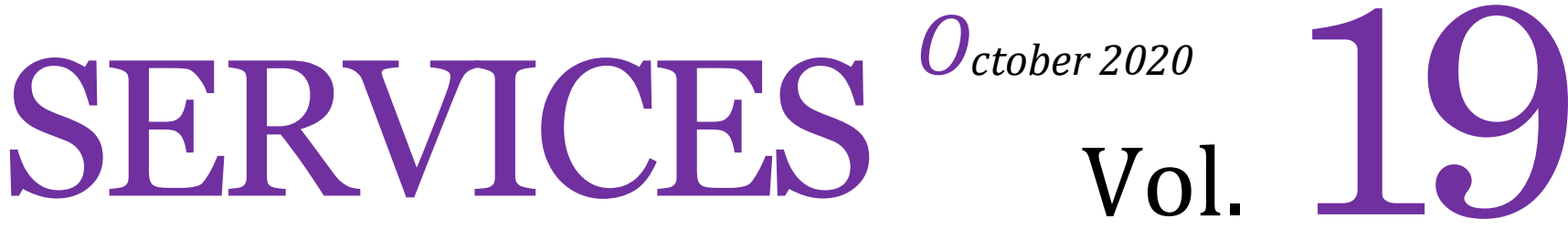

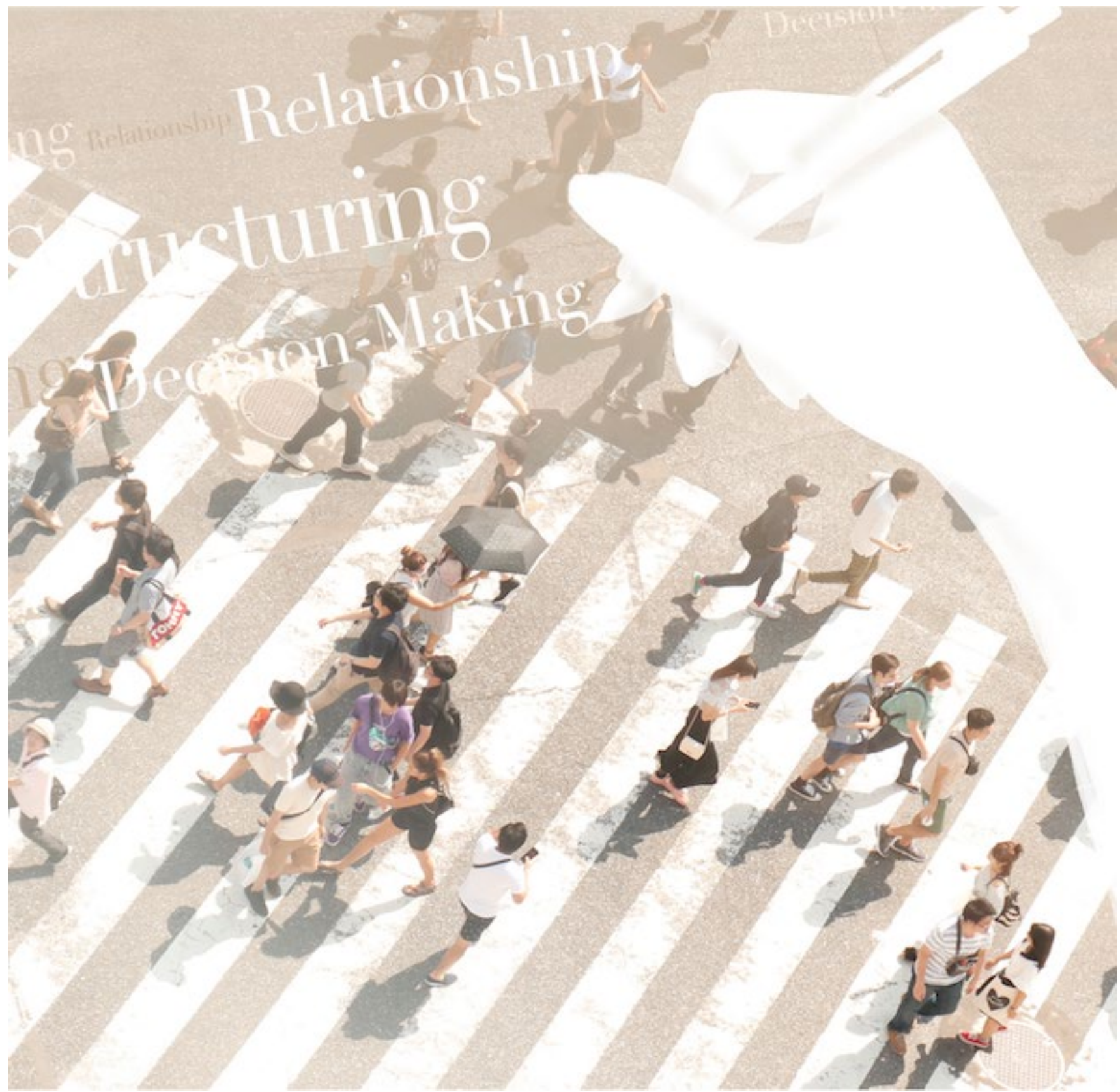


Original Article

\title{
Communication Gaps in Intersectoral Healthcare Professional Collaboration for Hospital Discharge Process of Patients With Dementia
}

\author{
Miki ARAZOE 1) Masami AMANO 2)
}

1) Department of Nursing in the Faculty of Health Sciences, Kyorin University, Japan

2) Department of Nursing in the Faculty of Nursing, Tokyo Junshin University, Japan

\begin{abstract}
The objective of this study was to discover communication gaps in interprofessional collaboration and examine ways to fill these gaps to mitigate communication difficulties in interprofessional collaboration during the discharge of patients with dementia (PWD) from hospital. The survey results obtained from 401 doctors, nurses, medical social workers (MSW), care managers, and visiting nurses were statistically analyzed. The analysis indicated the significant differences in "having knowledge of dementia" $(p<.01)$, "hospital discharge tends to be short notice" $(\mathrm{p}<.001)$, and "sufficient time spent in interprofessional discussions for the discharge of PWD" $(p<.01)$. As for the "things given importance upon discharge of PWD", "cardinal symptoms of dementia" $(p<.01)$, "feelings of the patients" $(p<.001)$, "feelings of family members" $(p<.001)$, "feelings of healthcare professionals" ( $p<.01)$, "support system for their families" $(p<.05)$, and "support system for the patients" $(p<.05)$ were significantly different, suggesting communication gaps among intersectoral healthcare professionals. It is critical to understand interprofessional differences in perspectives and thoughts about PWD to minimize communication gaps in interprofessional collaboration during discharge of PWD from hospital.
\end{abstract}

Received

February 14, 2020

Revised

August 28, 2020

Accepted

October 1, 2020

Published

October 30, 2020

$<$ Key-words $>$

patients with dementia, hospital discharge planning, interprofessional collaboration, communication, communication gap

arazoe@ks.kyorin-u.ac.jp (Miki ARAZOE; Japan) Asian J Human Services, 2020, 19:24-41. (C) 2020 Asian Society of Human Services 


\section{Introduction}

The Ministry of Health, Labour and Welfare (MHLW) 1) is promoting the establishment by 2025 of comprehensive systems to provide support and services that aid in the protection of dignity and independent living among the elderly (community comprehensive care system) in 2016, and therefore, the practice of team medical care and nursing care by health, medical and welfare practitioners is becoming ever more important. MHLW") introduced "A Comprehensive Strategy for the Promotion of Dementia Measures Towards a Community Friendly to the Elderly with Dementia, among others (The New Orange Plan)" for PWD with the principle idea of creating a society in which the desires and intentions of dementia persons are respected and they can continue living in familiar areas and environments as much as possible.

Therefore, comprehensive and continuous in-home medical and care support must be provided when PWD are discharged to go back to their home. Furthermore, delivery of appropriate services such as discharge planning and post-discharge support through interprofessional collaboration among medical healthcare and social workers within the region would be critical.

Yet nurses, pharmacists, radiologists and others who participated in team medical care training have expressed views on how it is "difficult to interact and collaborate with people in other fields" and how "communication is fundamental to multidisciplinary collaboration and cooperation, yet is the greatest challenge". Previous studies have outlined how role stress is experienced in collaborative work with care managers or nurses at elderly homes ${ }^{3}$, and how interprofessional collaboration can be challenging due to diffidence in the face of other professions and an inability to share information between team members ${ }^{4}$. Despite the need for interprofessional communication in team medical care, the level of achievement is still far from sufficient in practice.

In collaborative practice, information gaps occur due to differences in the amount of information that is conveyed or heard but not understood, as well as the degree of consultation and sharing that takes place; gaps in understanding occur due to different approaches to collaboration and professional role as well as different approaches and models (medical versus lifestyle) with respect to patients and how they should be prepared for discharge from the hospital. Such gaps in understanding explain why essential information is not conveyed, leading in turn to information gaps ${ }^{5}$. Therefore, when it comes to interprofessional collaboration in discharge planning for PWD, their differences in goals, perspectives on patients care, and ideas about whether to live at home or local houses are thought to lead into communication gaps, from which communication difficulties caused. Of all the communication gaps, particularly the gap in the level of understanding of dementia patients and their symptoms was thought to be substantial in the discharge process of patients with dementia relative to general patients. 
A communication gap can be defined as differences in knowledge, perspective, or lack of information leading to discrepancies in intended meaning which hinder supposedly mutually understandable communication ${ }^{6}$. Communication gaps can be classified into "information gap" where intended information is not conveyed properly, and "recognition gap" where cultural background, values, experiences, or recognition of problems differ between an originator and receiver of a communication ${ }^{7}$. PWD herein are patients hospitalized in a general ward who exhibit cardinal symptoms (e.g., memory impairment, disorientation) or behavioral and psychological symptoms (e.g., wandering, delusion, delirium, sleep impairment) of dementia.

\section{Objective}

The objective of this study is to investigate the methods to fill in communication gaps in interprofessional collaboration for hospital discharge of PWD by first finding out about the existing communication gaps.

\section{Method}

\section{Research design}

A cross-sectional study using a self-administered independent questionnaire of the International University of Health and Welfare.

\section{Respondents}

Total 2,500: 500 each of doctors, discharge support nurses, medical social workers (MSW), care managers, and visiting nurses employed nationwide at acute care hospitals with less than 400 beds.

Doctors, nurses and care managers were asked one by one from one hospital. In addition, the care manager, from the home office, visiting nurses, from the visiting nursing station, was asked by one each.

\section{Research period}

July to August 2017

\section{Content}

In the study, we created a survey based on the results obtained from previous researches to further investigate the communication gaps among intersectoral professionals engaging in the discharge process of PWD.

The response format used the 10-point Likert scale ranging from 1 strongly disagree to 
10 strongly agree. The attributes were the profession, number of years employed, age, sex, number of employees in the organization, the feasibility of interprofessional collaboration for the discharge of PWD.

\section{Data collection}

Surveys were sent to hospitals listed on the Japan Hospital Association roster, home care support service providers listed on nationwide rosters, and visiting nurse service providers listed on rosters maintained by prefectural health and welfare offices. Selections were made so as to avoid overlap between municipalities and achieve a balance in managing organizations. Requests for participation were sent by mail together with questionnaires and return envelopes to the director at each hospital or facility. Responses were collected on an anonymous basis by individual return envelope. Consent of the director was assumed upon the distribution of the questionnaires to respondents, and consent of the respondents was assumed upon return of the questionnaires by mail.

\section{Analysis}

Collected survey data were statistically analyzed using SPSS 23 software (one-way ANOVA, multiple comparisons).

\section{Ethical considerations}

All researchers involved in this study have abided by the Declaration of Helsinki and the Ethical Guidelines for Medical and Health Research Involving Human Subjects. The letter of request sent to respondents stated the purpose and method of research and explained that the study would be conducted only with permission of the respondent, that results would be strictly kept in locked storage until being shredded and destroyed after the later of 5 years following the conclusion of the study or 3 years from the final presentation of research, that results would be used only for purposes of this study, and that, although results would be presented at symposiums and in academic journals, data would be statistically processed so that no individual information would be unidentifiable. The letter further explained that participation was voluntary, that there were no unfavorable consequences to not responding, and that responses should be posted only with consent. There are no conflicts of interest associated with this research, and this study has been approved by the International University of Health and Welfare IRB (Approval Number: 17-Ig-24). 


\section{Results}

\section{Respondents}

There were 401 respondents in total: 38 doctors, 69 nurses, 71 MSW, 134 care managers and 89 visiting nurses (16.0\% response rate). Doctors ranged in age from their $30 \mathrm{~s}$ to $70 \mathrm{~s}$, with most in their 50s, while nurses and MSW ranged from their 20s to $60 \mathrm{~s}$ with most nurses in their 40s and 50s and most MSW in their 30s. Visiting nurses and care managers ranged from their 20s to $70 \mathrm{~s}$ with most in their 40s and 50s. Breakdown of sex, specialty and qualification are shown in Table 1.

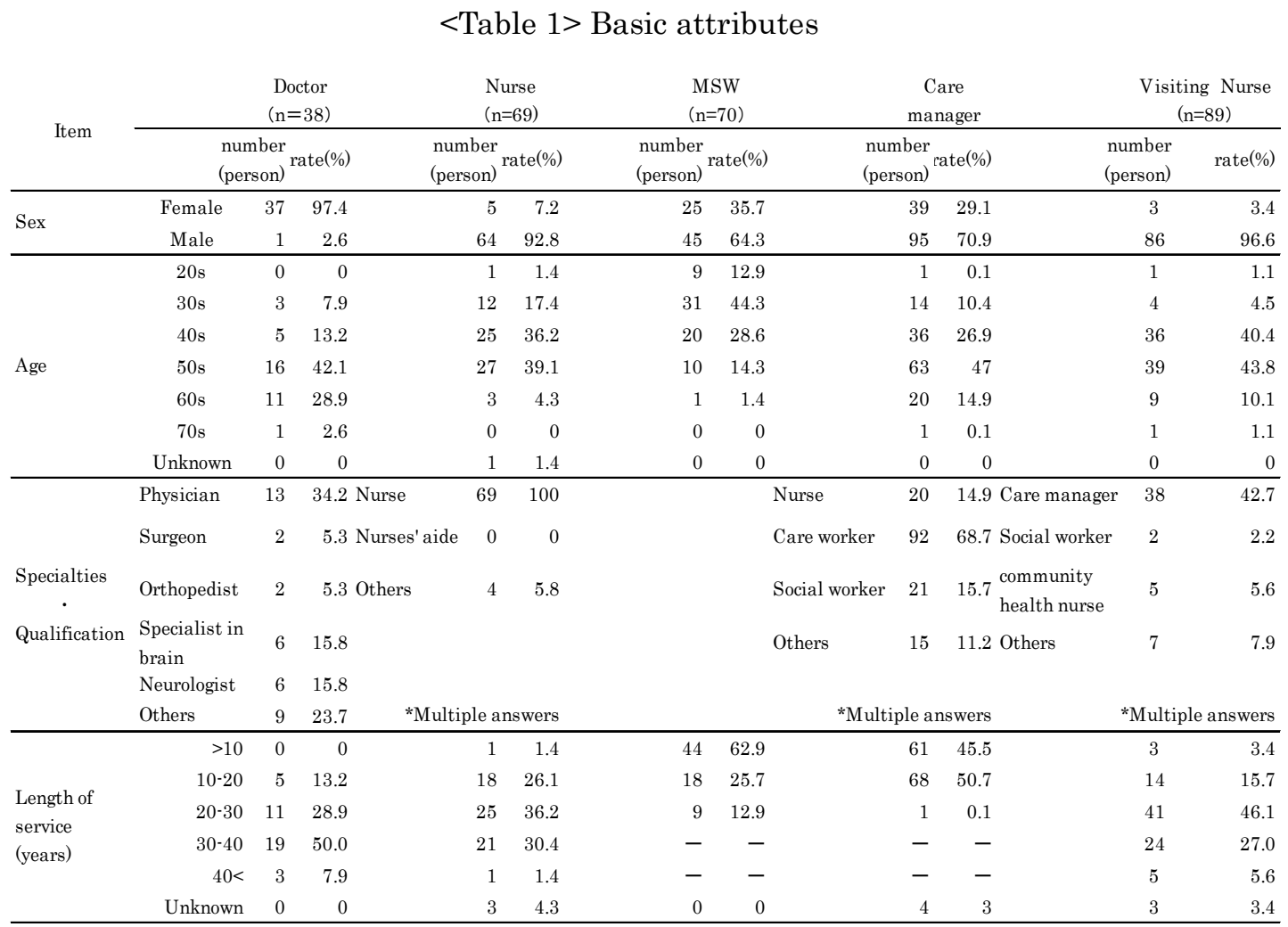

\section{Understanding of Dementia and Patients With Dementia}

The means and standard deviations for the "understanding of dementia and PWD" by each question for all professionals are as shown in Table 2.

The "(4) PWD often behave differently at hospital and at home" had a higher mean value of 8.2 than the other items with the lower mean values ranging from 5.5 to 6.6.

One way ANOVA was performed to evaluate the differences among the professions. The results showed the significant difference in "(1) Have knowledge of dementia" $(p<.01)$, "(2) Have knowledge of supportive care for symptoms of dementia" $(p<.05)$, “(6) Discharge date tend to be short-notice for PWD" $(p<.001)$, and “(7) Sufficient time spent 
in discussing the discharge plan for intersectional collaboration of PWD " $(\mathrm{p}<.01)$ while no significant difference was evident in the other questions (NS) (Table 2).

$<$ Table 2> Understanding of Dementia and Patients

With Dementia: mean and SD (all professions)

\begin{tabular}{lcc}
\hline & number & Mean \pm SD \\
\hline (1) Have knowledge of dementia & 399 & $6.6 \pm 1.74$ \\
(2) Have knowledge of supportive care for symptoms of dementia & 400 & $6.5 \pm 1.73$ \\
(3) Understand life with dementia & 399 & $6.5 \pm 1.72$ \\
& 400 & $8.2 \pm 1.65$ \\
(4) PWD often behave differently at hospital and at home & 400 & $6.2 \pm 1.74$ \\
(5) Know ways to provide discharge care for PWD & 397 & $6.3 \pm 2.35$ \\
(6) Discharge date tend to be short-notice for PWD & 397 & $5.9 \pm 1.86$ \\
(7) Sufficient time spent in discussing the discharge plan for intersectional collaboration of PWD & $* *$ \\
(8) Sense some difficulties in interprofessional collaboration for discharge process of PWD & 374 & $5.5 \pm 2.17$ \\
\hline One-way layout analysis of variance $* \mathrm{p}<.05 * * \mathrm{p}<$. 01 ***p $<$. 001 &
\end{tabular}

Based on the results obtained by multiple comparison for "(1) Have knowledge of dementia", doctors $7.2(\mathrm{SD}=1.89)$ and MSW 6.1 (SD = 1.78) were significantly different at $1 \%$ significant level, doctors and nurses $6.1(\mathrm{SD}=1.73)$ were significantly different at $5 \%$ significant level, and care managers $6.8(\mathrm{SD}=1.70)$ and MSW $6.1(\mathrm{SD}=1.70)$ were significantly different at $5 \%$ significant level $(\mathrm{F}=4.972, \mathrm{df}=4, \mathrm{p}<.05)$ (Table 3). The findings suggest that the doctors perceived themselves to have more knowledge of dementia than the nurses or the MSW, and the care managers perceived themselves to have more knowledge of dementia than the MSW.

As for the "(2) Have knowledge of supportive care for symptoms of dementia", the care managers 6.7 ( $\mathrm{SD}=1.75)$ and the MSW $6.0(\mathrm{SD}=1.80)$ were significantly different at the level of $5 \%(\mathrm{~F}=2.832, \mathrm{df}=4, \mathrm{p}<.05)$ suggesting that the care managers perceived themselves to have more knowledge of care for symptoms of dementia than the MSW.

As for the "(6) Discharge date tend to be short-notice for PWD", the visiting nurses 7.1 $(\mathrm{SD}=2.08)$ and doctors $5.2(\mathrm{SD}=1.97)$ were significantly different, and the visiting nurses and the MSW 5.5 ( $\mathrm{SD}=2.21)$ were significantly different at the level of $0.1 \%(\mathrm{~F}=$ $7.642, \mathrm{df}=4, \mathrm{p}<.001)$. The care managers $6.7(\mathrm{SD}=2.52)$ and doctors $5.2(\mathrm{SD}=1.97)$, the care managers and MSW 5.5 ( $\mathrm{SD}=2.21$ ) were also significantly different at the level of $1 \%(\mathrm{~F}=7.462, \mathrm{df}=4, \mathrm{p}<.01)$. Hence, the visiting nurses and care managers recognized that discharge date tend to be short-notice for PWD.

As for the "(7) Sufficient time spent in discussing the discharge plan for intersectional collaboration of PWD ", the visiting nurses 5.3 ( $\mathrm{SD}=1.95)$ and doctors $6.6(\mathrm{SD}=1.64)$, and the nurses and care managers $5.9(\mathrm{SD}=1.99)$ were significantly different at the level 
of $5 \%(\mathrm{~F}=4.249, \mathrm{df}=4, \mathrm{p}<.05)$, suggesting that the visiting nurses perceived more than the doctors or care managers that the discharge plan for PWD was not sufficiently discussed.

$<$ Table $3>$ Understanding of Dementia and Patients With Dementia

\begin{tabular}{|c|c|c|c|c|c|c|}
\hline & & number & Mean \pm & SD & $\mathrm{F}$ & \\
\hline \multirow{5}{*}{ (1) Have knowledge of dementia } & Doctor & 37 & 7.2 & 1.89 & & \multirow{5}{*}{]$\left.^{*}\right]^{* *}$} \\
\hline & Nurse & 67 & 6.1 & 1.73 & & \\
\hline & visiting nurse & 90 & 6.8 & 1.58 & 4.972 & \\
\hline & Care manager & 134 & 6.8 & 1.70 & & \\
\hline & MSW & 71 & 6.1 & 1.78 & & \\
\hline \multirow{5}{*}{$\begin{array}{l}\text { (2) Have knowledge of supportive care for symptoms } \\
\text { of dementia }\end{array}$} & Doctor & 37 & 6.7 & 1.91 & & \multirow{5}{*}{$7^{*}$} \\
\hline & Nurse & 68 & 6.2 & 1.55 & & \\
\hline & visiting nurse & 90 & 6.7 & 1.64 & 2.832 & \\
\hline & Care manager & 134 & 6.7 & 1.75 & & \\
\hline & MSW & 71 & 6.0 & 1.80 & & \\
\hline \multirow{5}{*}{ (3) Understand the life with dementia } & Doctor & 37 & 6.6 & 1.83 & & \multirow{5}{*}{$n \cdot s$} \\
\hline & Nurse & 68 & 6.2 & 1.52 & & \\
\hline & visiting nurse & 90 & 6.7 & 1.68 & 2.315 & \\
\hline & Care manager & 133 & 6.7 & 1.73 & & \\
\hline & MSW & 71 & 6.2 & 1.79 & & \\
\hline \multirow{5}{*}{ (4) PWD often behave differently at hospital and at home } & Doctor & 37 & 8.0 & 1.52 & & \multirow{5}{*}{$\mathrm{n} \cdot \mathrm{s}$} \\
\hline & Nurse & 68 & 7.9 & 1.77 & & \\
\hline & visiting nurse & 90 & 8.3 & 1.64 & 1.226 & \\
\hline & Care manager & 134 & 8.3 & 1.66 & & \\
\hline & MSW & 71 & 8.1 & 1.59 & & \\
\hline \multirow{5}{*}{ (5) Know ways to provide discharge care for PWD } & Doctor & 37 & 6.4 & 1.90 & & \multirow{5}{*}{$n \cdot s$} \\
\hline & Nurse & 68 & 6.0 & 1.38 & & \\
\hline & visiting nurse & 90 & 6.1 & 1.93 & .877 & \\
\hline & Care manager & 134 & 6.4 & 1.71 & & \\
\hline & MSW & 71 & 6.2 & 1.75 & & \\
\hline \multirow{5}{*}{ (6) Discharge date tend to be short-notice for PWD } & Doctor & 37 & 5.2 & 1.97 & & \multirow{5}{*}{]$^{* * \pi} * * *$} \\
\hline & Nurse & 68 & 6.1 & 2.18 & & \\
\hline & visiting nurse & 88 & 7.1 & 2.08 & 8.065 & \\
\hline & Care manager & 133 & 6.7 & 2.52 & & \\
\hline & MSW & 71 & 5.5 & 2.21 & & \\
\hline \multirow{5}{*}{$\begin{array}{l}\text { (7) Sufficient time spent in discussing the discharge plan } \\
\text { for intersectional collaboration of PWD }\end{array}$} & Doctor & 37 & 6.6 & 1.64 & & \multirow{5}{*}{]$_{*}^{* *}$} \\
\hline & Nurse & 68 & 6.0 & 1.67 & & \\
\hline & visiting nurse & 88 & 5.3 & 1.95 & 4.249 & \\
\hline & Care manager & 133 & 5.9 & 1.99 & & \\
\hline & MSW & 71 & 6.0 & 1.56 & & \\
\hline \multirow{5}{*}{$\begin{array}{l}\text { (8) Sense some difficulties in interprofessional } \\
\text { collaboration for discharge process of PWD }\end{array}$} & Doctor & 37 & 4.8 & 1.96 & & \multirow{5}{*}{ n.s. } \\
\hline & Nurse & 68 & 5.9 & 2.05 & & \\
\hline & visiting nurse & 82 & 5.7 & 1.90 & 2.666 & \\
\hline & Care manager & 120 & 5.2 & 2.36 & & \\
\hline & MSW & 67 & 5.7 & 2.25 & & \\
\hline
\end{tabular}

One-way ANOVA host hoc assay (multiple comparison) ${ }^{*} \mathrm{p}<.05,{ }^{* *} \mathrm{p}<.01,{ }^{* * *} \mathrm{p}<.001$ 


\section{Things Emphasized in Discharge of PWD}

The mean values and standard deviations for the "things emphasized in the discharge of PWD" are as shown in Table 4.

Of the things emphasized in discharge of PWD, the followings had the higher mean value of 8.0 or above: (1) illness and its symptoms that lead to hospitalization, (2) cardinal symptoms of dementia (e.g., memory impairment, disorientation), (3) behavioral and psychological symptoms of dementia (e.g., wandering, delusion, delirium, sleep impairment), (4) feelings of PWD, (5) feelings of PWD family, (7) support system for PWD, (8) support system for PWD family, (10) financial condition, (12) circumstances unique to each PWD and their family.

One way ANOVA was performed to evaluate the differences among the professions. The results suggested that (2) cardinal symptoms of dementia (e.g., memory impairment, disorientation) ( $p<.01)$, (4) feelings of PWD $(p<.001)$, (5) feelings of PWD family $(p$ $<.001$ ), (6) feelings of healthcare professionals, $(\mathrm{p}<.01)$, (7) support system for PWD (p $<.05)$, (8) support system for PWD family $(\mathrm{p}<.05)$, (9) support system for community (p $<.001$ ), (11) issues such as hospital occupancy ( $<.01$ ), and (13) experiences of MSW or care managers $(p<.05)$ were significantly different (Table 4$)$.

$<$ Table 4> Things Given Importance Upon

Discharge of PWD: mean and SD (all professions)

\begin{tabular}{|c|c|c|c|c|}
\hline & number & Mean & $\pm \mathrm{SD}$ & \\
\hline (1) illness and its symptoms that lead to hospitalization & 394 & 8.3 & 1.62 & \\
\hline (2) cardinal symptoms of dementia (e.g., memory impairment, disorientation) & 396 & 8.3 & 1.56 & $* *$ \\
\hline $\begin{array}{l}\text { (3) behavioral and psychological symptoms of dementia } \\
\text { (e.g., wandering, delusion, delirium, sleep impairment) }\end{array}$ & 397 & 8.6 & 1.42 & \\
\hline (4) feelings of PWD & 397 & 8.3 & 1.72 & $* * *$ \\
\hline (5) feelings of PWD family & 398 & 8.7 & 1.28 & $* * *$ \\
\hline (6) feelings of healthcare professionals & 391 & 7.0 & 1.88 & ** \\
\hline (7) support system for PWD & 396 & 8.8 & 1.34 & * \\
\hline (8) support system for PWD family & 396 & 8.7 & 1.38 & * \\
\hline (9) support system for community & 389 & 7.1 & 2.06 & $* * *$ \\
\hline (10) financial condition & 397 & 8.3 & 1.60 & \\
\hline (11) issues such as hospital occupancy & 389 & 6.8 & 2.14 & $* *$ \\
\hline (12) circumstances unique to each PWD and their family & 394 & 8.4 & 1.40 & \\
\hline (13) experiences of MSW or care managers & 386 & 6.3 & 2.21 & * \\
\hline
\end{tabular}

One-way layout analysis of variance ${ }^{*} \mathrm{p}<.05{ }^{* *} \mathrm{p}<.01 * * * \mathrm{p}<.001$ 
Based on the results obtained by multiple comparison for "(2) cardinal symptoms of dementia (e.g., memory impairment, disorientation)", the doctors $7.6(\mathrm{SD}=1.70)$ and the visiting nurses $8.8(\mathrm{SD}=1.36)$ were significantly different at the level of $1 \%(\mathrm{~F}=4.455, \mathrm{df}$ $=4, \mathrm{p}<.01)$, doctors $7.6(\mathrm{SD}=1.70)$ and care managers $8.4(\mathrm{SD}=1.61)$ were significantly different at the level of $5 \%(\mathrm{~F}=4.455, \mathrm{df}=4, \mathrm{p}<.05)$ (Table 5$)$. The findings suggest that the visiting nurses and care managers placed more importance on the cardinal symptoms of dementia (e.g., memory impairment, disorientation) than the doctors.

As for the "(4) feelings of PWD", the visiting nurses 8.7 (SD = 1.43) and doctors 7.3 (SD $=1.93)$, as well as care managers $8.5(\mathrm{SD}=1.70)$ and doctors were significantly different at the level of $1 \%(\mathrm{~F}=7.475, \mathrm{df}=4, \mathrm{p}<0.01)$. In addition, the visiting nurses 8.7 (SD $=$ 1.43) and the MSW 7.7 ( SD = 1.83) were significantly different at the level of $1 \%(\mathrm{~F}=$ 7.475 , $\mathrm{df}=4, \mathrm{p}<0.01)$, the care managers $8.5(\mathrm{SD}=1.70)$ and the MSW $7.7(\mathrm{SD}=1.83)$ were significantly different at the level of $5 \%(\mathrm{~F}=7.475, \mathrm{df}=4, \mathrm{p}<0.05)$. The findings suggest that visiting nurses and care managers placed more importance on the feelings of PWD than the MSW and doctors. As for the "(5) feelings of PWD family", the visiting nurses $9.1(\mathrm{SD}=1.15)$ and the care managers $9.0(\mathrm{SD}=1.25)$, as well as the visiting nurses and the doctors $7.9(\mathrm{SD}=1.50)$ were significantly different at the level of $1 \%(\mathrm{~F}=$ $6.826, \mathrm{df}=4, \mathrm{p}<0.01)$. The findings suggest that visiting nurses and care managers placed more importance on the feelings of the PWD family than the doctors.

In addition, as for the "(6) feelings of healthcare professionals", the visiting nurses 7.3 $(\mathrm{SD}=1.92)$ and the doctors $6.1(\mathrm{SD}=1.88)$ were significantly different at the level of $1 \%$ $(\mathrm{F}=3.646, \mathrm{df}=4, \mathrm{p}<0.01)$, the nurses $7.2(\mathrm{SD}=1.81)$ and the doctors, as well as the MSW 7.1 $(\mathrm{SD}=1.76)$ and the doctors were significantly different at the level of $5 \%(\mathrm{~F}=$ $3.646, \mathrm{df}=4, \mathrm{p}<0.05)$. The findings suggest that the visiting nurses, nurses, and MSW emphasized more on the feelings of healthcare professionals than the doctors. 
DOI: http://dx.doi.org/10.14391/ajhs.19.24

Asian Journal of Human Services, VOL.19 24-41

$<$ Table 5> Things Given Importance Upon Discharge of PWD

\begin{tabular}{|c|c|c|c|c|c|c|}
\hline & & number & Mean \pm & $=\mathrm{SD}$ & $\mathrm{F}$ & \\
\hline \multirow{5}{*}{$\begin{array}{l}\text { (1) illness and its symptoms that lead to } \\
\text { hospitalization }\end{array}$} & Doctor & 38 & 7.8 & 1.74 & \multirow{5}{*}{1.499} & \multirow{5}{*}{ n.s. } \\
\hline & Nurse & 68 & 8.3 & 1.57 & & \\
\hline & visiting nurse & 89 & 8.5 & 1.60 & & \\
\hline & Care manager & 129 & 8.4 & 1.58 & & \\
\hline & MSW & 70 & 8.2 & 1.65 & & \\
\hline \multirow{5}{*}{$\begin{array}{l}\text { (2) cardinal symptoms of dementia } \\
\text { (e.g., memory impairment, disorientation) }\end{array}$} & Doctor & 38 & 7.6 & 1.70 & \multirow{5}{*}{$4.455]$} & \\
\hline & Nurse & 69 & 8.2 & 1.58 & & \\
\hline & visiting nurse & 90 & 8.8 & 1.36 & & \\
\hline & Care manager & 129 & 8.4 & 1.61 & & \\
\hline & MSW & 70 & 8.2 & 1.49 & & \\
\hline \multirow{5}{*}{$\begin{array}{l}\text { (3) behavioral and psychological symptoms of dementia } \\
\text { (e.g., wandering, delusion, delirium, sleep impairment) }\end{array}$} & Doctor & 38 & 8.2 & 1.45 & \multirow{5}{*}{1.955} & \multirow{5}{*}{ n.s. } \\
\hline & Nurse & 69 & 8.5 & 1.52 & & \\
\hline & visiting nurse & 89 & 8.9 & 1.31 & & \\
\hline & Care manager & 131 & 8.6 & 1.43 & & \\
\hline & MSW & 70 & 8.6 & 1.38 & & \\
\hline \multirow{5}{*}{ (4) feelings of PWD } & Doctor & 38 & 7.3 & 1.93 & \multirow{5}{*}{7.475} & \\
\hline & Nurse & 69 & 8.3 & 1.56 & & \\
\hline & visiting nurse & 90 & 8.7 & 1.43 & & * \\
\hline & Care manager & 130 & 8.5 & 1.70 & & \\
\hline & MSW & 70 & 7.7 & 1.83 & & \\
\hline \multirow{5}{*}{ (5) feelings of PWD family } & Doctor & 38 & 7.9 & 1.50 & \multirow{5}{*}{6.826} & \\
\hline & Nurse & 69 & 8.6 & 1.31 & & \\
\hline & visiting nurse & 90 & 9.0 & 1.15 & & $* * *$ \\
\hline & Care manager & 131 & 9.0 & 1.25 & & \\
\hline & MSW & 70 & 8.5 & 1.15 & & \\
\hline & Doctor & 38 & 6.1 & 1.88 & & 7 \\
\hline & Nurse & 69 & 7.2 & 1.81 & & * \\
\hline (6) feelings of healthcare professionals & visiting nurse & 88 & 7.3 & 1.92 & 3.646 & * \\
\hline & Care manager & 126 & 6.8 & 1.88 & & \\
\hline & MSW & 70 & 7.1 & 1.76 & & \\
\hline & Doctor & 38 & 8.3 & 1.31 & & \\
\hline & Nurse & 69 & 8.9 & 1.23 & & * \\
\hline (7) support system for PWD & visiting nurse & 90 & 9.0 & 1.18 & 2.357 & \\
\hline & Care manager & 129 & 8.7 & 1.54 & & \\
\hline & MSW & 70 & 8.8 & 1.20 & & \\
\hline & Doctor & 38 & 8.2 & 1.39 & & \\
\hline & Nurse & 69 & 8.9 & 1.19 & & \\
\hline (8) support system for PWD family & visiting nurse & 89 & 8.9 & 1.22 & 2.756 & n.s. \\
\hline & Care manager & 130 & 8.8 & 1.50 & & \\
\hline & MSW & 70 & 8.5 & 1.44 & & \\
\hline & Doctor & 38 & 7.4 & 1.54 & & \\
\hline & Nurse & 68 & 7.8 & 1.60 & & \\
\hline (9) support system for community & visiting nurse & 89 & 7.5 & 1.83 & 5.141 & 7 \\
\hline & Care manager & 124 & 6.5 & 2.26 & & $*$ \\
\hline & MSW & 70 & 7.0 & 2.36 & & \\
\hline & Doctor & 38 & 7.7 & 1.37 & & \\
\hline & Nurse & 69 & 8.2 & 1.46 & & \\
\hline (10) financial condition & visiting nurse & 90 & 8.2 & 1.61 & 2.161 & n.s. \\
\hline & Care manager & 130 & 8.4 & 1.73 & & \\
\hline & MSW & 70 & 8.6 & 1.50 & & \\
\hline & Doctor & 38 & 6.9 & 1.76 & & \\
\hline & Nurse & 69 & 7.4 & 1.81 & & \\
\hline (11) issues such as hospital occupancy & Health visitor & 86 & 6.4 & 2.52 & 3.302 & 7 \\
\hline & Care manager & 126 & 6.5 & 2.25 & & \rfloor \\
\hline & MSW & 70 & 7.1 & 1.74 & & \\
\hline & Doctor & 38 & 7.9 & 1.17 & & \\
\hline & Nurse & 68 & 8.2 & 1.37 & & \\
\hline (12) circumstances unique to each PWD and their family & visiting nurse & 90 & 8.6 & 1.32 & 2.256 & n.s. \\
\hline & Care manager & 128 & 8.5 & 1.51 & & \\
\hline & MSW & 70 & 8.3 & 1.39 & & \\
\hline & Doctor & 38 & 6.8 & 1.73 & & \\
\hline & Nurse & 67 & 6.8 & 2.03 & & \\
\hline (13) experiences of MSW or care managers & visiting nurse & 90 & 6.4 & 2.31 & 2.767 & \\
\hline & Care manager & 123 & 5.9 & 2.44 & & \\
\hline & MSW & 68 & 6.4 & 1.91 & & \\
\hline
\end{tabular}




\section{Things considered critical for interprofessional collaboration in the discharge of PWD}

The mean values and standard deviations for "the things considered critical for interprofessional collaboration in the discharge of PWD" are as shown in Table 6.

The mean values were high, 8.0 or above, for all the items except for the "(6) collaborative leadership" and "(7) resolving the interprofessional conflict".

One way ANOVA was performed to evaluate the differences among the professions. The results indicated that "(8) joined conference" was significantly different $(p<.001)$, while no significant difference was evident in the other items (NS) (Table 6).

$<$ Table 6> Things Considered Critical for Interprofessional Collaboration: mean and SD (all professions)

\begin{tabular}{|c|c|c|c|c|}
\hline & number & Mean & $\pm \mathrm{SD}$ & \\
\hline (1) expertise knowledge & 395 & 8.1 & 1.62 & \\
\hline (2) expertise & 395 & 8.2 & 1.58 & \\
\hline (3) interprofessional communication & 395 & 8.8 & 1.37 & \\
\hline (4) common goal setting & 394 & 8.6 & 1.54 & \\
\hline (5) defining the role of each profession & 393 & 8.1 & 1.70 & \\
\hline (6) collaborative leadership & 387 & 7.5 & 1.77 & \\
\hline (7) resolving the interprofessional conflict & 389 & 7.4 & 1.90 & \\
\hline (8) joined conference & 393 & 8.3 & 1.67 & $* * *$ \\
\hline
\end{tabular}

One-way layout analysis of variance ${ }^{*} \mathrm{p}<.05{ }^{* *} \mathrm{p}<.01{ }^{* * *} \mathrm{p}<.001$

Based on the results obtained by multiple comparison for the "(8) joined conference", the nurses $8.9(\mathrm{SD}=1.28)$, MSW $8.5(\mathrm{SD}=1.48)$ and doctors $7.5(\mathrm{SD}=1.56)$ were significantly different at the level of $1 \%(\mathrm{~F}=4.569, \mathrm{df}=4, \mathrm{p}<.01)$. The nurses $8.9(\mathrm{SD}=$ $1.28)$ and care managers $8.1(\mathrm{SD}=1.89)$ were significantly different at the level of $5 \%(\mathrm{~F}$ $=4.569, \mathrm{df}=4, \mathrm{p}<.05$ ) (Table 7). The findings suggested that the nurses and MSW considered a joined conference for discharge planning more important than the doctors. Furthermore, the nurses (discharge planning) considered a joined conference more important than the MSW.

Things considered critical for interprofessional collaboration in the discharge of PWD are shown by profession from highest to lowest priority according to their mean scores in Figure 1.

All professions except MSW answered that the "(3) interprofessional communication" is their top priority followed by "(4) common goal setting". The order of priority for "(8) joined conference" varied among the professions. The care managers placed a high priority on "(5) defining the role of each profession" than the other professions. 
$<$ Table 7> Things Considered Critical for Interprofessional

Collaboration Upon Discharge of PWD

\begin{tabular}{|c|c|c|c|c|c|c|}
\hline & & number & Mean \pm & SD & $\mathrm{F}$ & \\
\hline \multirow{5}{*}{ 1) expertise knowledge } & Doctor & 38 & 7.7 & 1.63 & \multirow{5}{*}{2.265} & \multirow{5}{*}{ n.s. } \\
\hline & Nurse & 68 & 8.5 & 1.40 & & \\
\hline & visiting nurse & 89 & 8.3 & 1.53 & & \\
\hline & Care manager & 132 & 8.0 & 1.73 & & \\
\hline & MSW & 68 & 7.9 & 1.65 & & \\
\hline \multirow{5}{*}{ 2) expertise } & Doctor & 38 & 7.8 & 1.52 & \multirow{5}{*}{1.974} & \multirow{5}{*}{ n.s. } \\
\hline & Nurse & 68 & 8.5 & 1.35 & & \\
\hline & visiting nurse & 90 & 8.3 & 1.53 & & \\
\hline & Care manager & 131 & 8.1 & 1.71 & & \\
\hline & MSW & 68 & 7.9 & 1.59 & & \\
\hline \multirow{5}{*}{ 3) interprofessional communication } & Doctor & 38 & 8.5 & 1.25 & \multirow{5}{*}{2.329} & \multirow{5}{*}{ n.s. } \\
\hline & Nurse & 68 & 9.1 & 1.21 & & \\
\hline & visiting nurse & 90 & 8.9 & 1.25 & & \\
\hline & Care manager & 131 & 8.8 & 1.51 & & \\
\hline & MSW & 68 & 8.4 & 1.42 & & \\
\hline \multirow{5}{*}{ 4) common goal setting } & Doctor & 38 & 8.1 & 1.40 & \multirow{5}{*}{2.066} & \multirow{5}{*}{ n.s. } \\
\hline & Nurse & 69 & 9.0 & 1.29 & & \\
\hline & visiting nurse & 89 & 8.7 & 1.51 & & \\
\hline & Care manager & 131 & 8.5 & 1.69 & & \\
\hline & MSW & 67 & 8.5 & 1.52 & & \\
\hline \multirow{5}{*}{ 5) defining the role of each profession } & Doctor & 38 & 7.7 & 1.53 & \multirow{5}{*}{1.188} & \multirow{5}{*}{ n.s. } \\
\hline & Nurse & 68 & 8.3 & 1.59 & & \\
\hline & visiting nurse & 89 & 8.2 & 1.64 & & \\
\hline & Care manager & 130 & 8.2 & 1.76 & & \\
\hline & MSW & 68 & 7.8 & 1.82 & & \\
\hline \multirow{5}{*}{ 6) collaborative leadership } & Doctor & 38 & 7.7 & 1.62 & \multirow{5}{*}{1.984} & \multirow{5}{*}{ n.s. } \\
\hline & Nurse & 67 & 7.8 & 1.40 & & \\
\hline & visiting nurse & 89 & 7.8 & 1.69 & & \\
\hline & Care manager & 125 & 7.4 & 1.94 & & \\
\hline & MSW & 68 & 7.2 & 1.89 & & \\
\hline \multirow{5}{*}{ 7) resolving the interprofessional conflict } & Doctor & 38 & 7.2 & 1.66 & \multirow{5}{*}{1.000} & \multirow{5}{*}{ n.s. } \\
\hline & Nurse & 68 & 7.5 & 1.71 & & \\
\hline & visiting nurse & 88 & 7.6 & 2.01 & & \\
\hline & Care manager & 129 & 7.2 & 1.98 & & \\
\hline & MSW & 66 & 7.3 & 1.90 & & \\
\hline \multirow{5}{*}{ 8) joined conference } & Doctor & 38 & 7.5 & 1.56 & \multirow{5}{*}{4.569} & \\
\hline & Nurse & 67 & 8.9 & 1.28 & & $* * *$ \\
\hline & visiting nurse & 89 & 8.4 & 1.65 & & * \\
\hline & Care manager & 131 & 8.1 & 1.89 & & \\
\hline & MSW & 68 & 8.5 & 1.48 & & 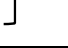 \\
\hline
\end{tabular}

One-way ANOVA host hoc assay (multiple comparison) ${ }^{*} \mathrm{p}<.05,{ }^{* *} \mathrm{p}<.01,{ }^{* * *} \mathrm{p}<.001$ 


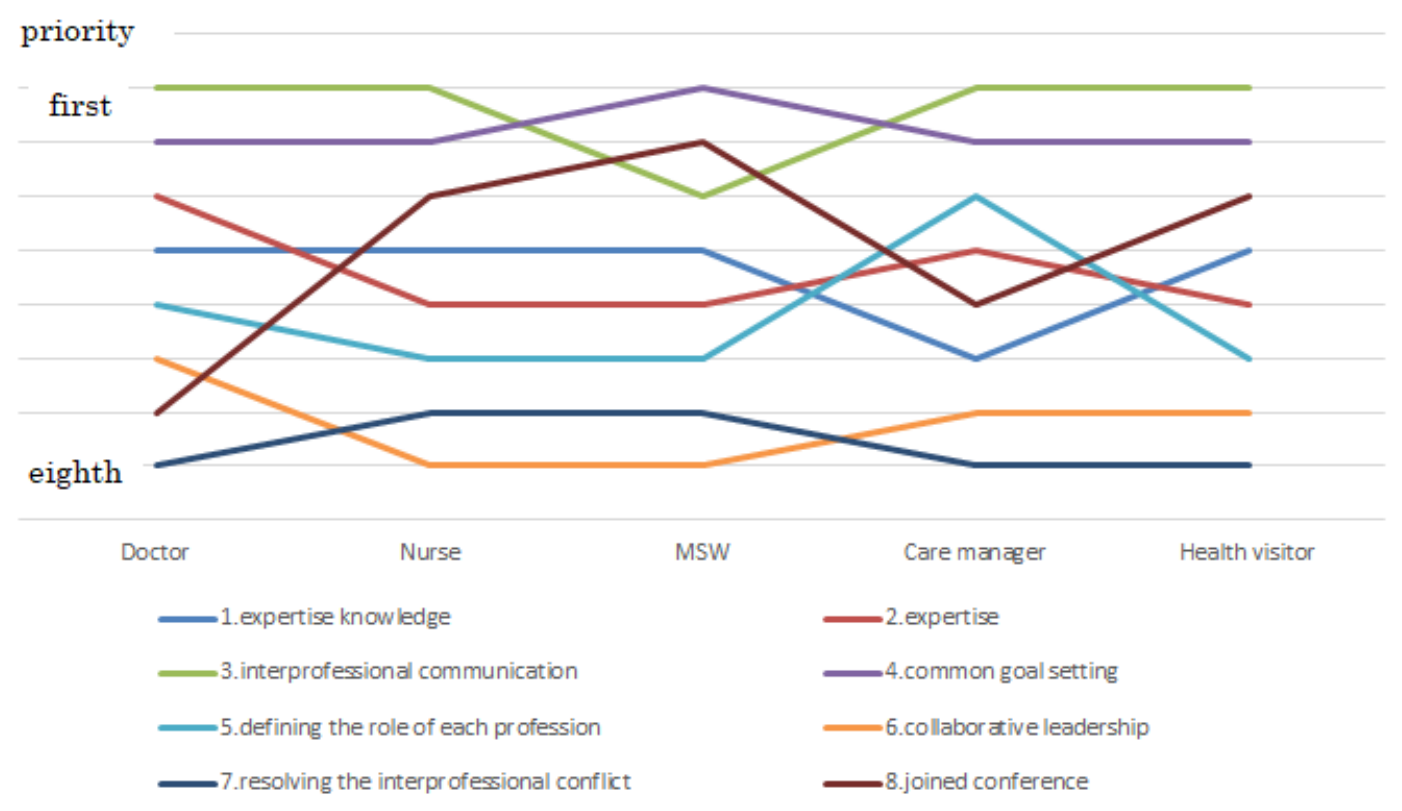

$<$ Figure 1 $>$ Things Considered Critical for Interprofessional Collaboration Upon Discharge of PDW (The order of priority by profession)

\section{Discussion}

\section{Understanding of Dementia and Patients With Dementia}

Understanding of dementia and PWD was different in perception by job type, with "Have knowledge of dementia." and "Have knowledge of supportive care for symptoms associated with dementia." Moreover, perceptions including the symptoms that are not regarded as dementia at home are diagnosed as dementia in the hospital and considered a problem or, symptoms that are not dementia are diagnosed as dementia might lead to the recognition, patients with dementia are increasing8). In this way, even if you think that you are "Have knowledge of dementia" or "Have knowledge of supportive care for symptoms of dementia", the dementia and symptoms of dementia are not as texted, and each person's symptoms are different.

It was also thought that there was a difference in the perception of job categories by actually experiencing PWD, as if they recognized that "PWD is different in the behavior of hospitals and homes." As Arita et al. ${ }^{9}$ note, in most hospitals, for any one patient, there are multiple directly and indirectly involved personnel who hail from multiple specialties and multiple positions. Interactions with the patient differ for each profession, and acquired information is limited and changes over time. Differences in perceptions for [Patient] may be related to differences in the quality and quantity of information that can be obtained by each profession depending on the patient's condition and response.

With respect to patient discharge from the hospital, visiting nurses perceived most 
strongly that "Discharge date of PWD tend to be short-notice", followed by care managers, with doctors having the weakest perception. Since schedules are determined by doctors based on the treatment program, they do not perceive that patients are discharged suddenly. For practitioners that have to follow the doctor's orders and make arrangements for discharge with families and other parties outside of the hospital, however, the perception is that there is not enough time to prepare.

\section{Things Given Importance Upon Discharge of PWD}

As discharge coordination for PWD, the visiting nurses and care managers placed more importance on the cardinal symptoms of dementia (memory impairment, disorientation, among others), feelings of PWD, their families, and healthcare professionals than the doctors. Hosoda ${ }^{10)}$ noted that team medical care consists of the following four components: (1) expertise-oriented component to utilize expertise of each field, (2) patient-oriented component to prioritize patients' needs, (3) occupation-oriented component to include various occupations to make up a team, and (4) cooperation-oriented to focus on various professionals to work together collaboratively on equal footing. Depending on which component each professional emphasizes, antinomic tension may rise, or there may be a case where fulfillment of one component may lead to unfulfillment of another component. Such variation of emphasis by each profession is thought to cause communication gaps.

It is also reported that despite the families' willingness to care PWD at home upon their hospital discharge, they are also reluctant of discharge considering the burden on the families ${ }^{11}$. Therefore, it was thought that the average of care managers and visiting nurses who were actually involved with the family was higher, and this difference in perception also led to a communication gap.

Saito et al. ${ }^{12)}$ state that interprofessional collaboration in the continuity of hospital discharge support is critical because the post-discharge life of PWD can vary substantially depending on many factors such as severity of dementia, the conditions of behavioral and psychological symptoms, medication requirement, residing family members, or financial status. Therefore, it is important to examine further the ways to provide help and support for PWD by the improved interprofessional collaboration to reduce the anxiety of PWD and their families upon discharge.

\section{Things Considered Critical for Interprofessional Collaboration in Discharge of PWD}

In what I think is important in the cooperation between occupations for the discharge of PWD, there was a difference by the occupation albeit in "Joint conference". In many cases when elderly patients with dementia are discharged from the hospital, their husband or wife also tend to have dementia. Furthermore, the number of older adults living alone has been increasing recently, which might lead to difficulties in discharge coordination for patients with dementia.

Matsuoka ${ }^{13)}$ stated that most patients with dementia are older adults having various 
chronic diseases and a decline in physical functions. Therefore, an interprofessional team approach is required for managing their physical and various psychological and social care needs, including problems related to nursing care.In this way, it is important to work together between occupational positions toward the discharge of PWD, and in fact, the coordination of discharge of PWD was not so important. I think that it is connected though it is important that the cooperation between occupational categories is difficult in the schedule.

Things considered most critical by all the professionals except MSW for interprofessional collaboration in the discharge of PWD was "communication" followed by "sharing the same goal". Although most of the professionals are aware of the importance of communication, having effective communication is difficult which may be the exact reason why such communication is valued.

Communicational skill education in medical consultation interviews for doctors, for instance, began in the early 1990s and gradually pervaded from there. According to Nagashima et al. ${ }^{14}$ ), however, communication education provided for doctors before and after graduation is mainly to give medical consultation and not to promote effective dialog skills. For visiting-nurses renewed Investigative Commission for Enrichment of Basic Nursing Education ${ }^{15}$ ) released in 2007 incorporated educational curriculum for better communication abilities. Although communication education nowadays is advancing, as shown above, additional education is necessary not only for the communication between healthcare professionals and patients or their families but also for the communication between healthcare professionals. Not only knowledge but communication skills and abilities must be cultivated deliberate communication.

\section{Minimizing Communication Gaps in Interprofessional Healthcare Professionals}

The study found that there are differences in perceptions of dementia and PWD among medical and welfare professionals. As Hosoda ${ }^{16)}$ says, specialists often have a different educational background with their own different values and opinions which may be one of the reasons why interprofessional collaboration can be difficult. Although more education on communication or interprofessional collaboration is becoming more accessible through lectures and practical training, they are still conducted independently for each profession. Hence, there should be more opportunity for various professionals to learn together. Although acquiring knowledge through a lecture is essential, the essential part of gaining understanding in communication is understanding by knowledge gained from actual experiences by seeing and feeling via practical training at the workplace. Such experiences also help each other to understand and learn the role of each profession.

One of the examples of different values and ideas of each profession is that medical professionals value more of the traditional "medical model (pathological model)" focusing on individuals undergoing struggling life circumstances whereas social welfare workers 
tend to value more of "ecological model" than "pathological model". The "ecological model" aims to understand problems by emphasizing the humans and environmental transaction, and enhancing adaptability and tolerance-responsiveness of humans through intervening the interface between humans and environment for better transition quality ${ }^{17)}$.

While medical professionals try to resolve issues by focusing on the problems an individual may be having and its cause, social welfare professionals not only focus on the weaknesses adverse conditions of their clients but also focus on their clients' ability (including not only individual but also groups and local communities), willingness, preference, available social resources and other strengths. The early part of hospitalization starts with team medical treatment care model to aim for the earliest recovery possible. When full rehabilitation process begins as the condition gradually ameliorates, the medical model is not sufficient in terms of support for post-discharge life of PWD, which requires alternation of the medical model into the biological, psychological and social model ${ }^{18}$. The approaches for PWD and their discharge process need to be changed accordingly as PWD undergo different phases from hospitalization to discharge.

\section{Conclusion}

The results indicated that there was a significant difference in "Have knowledge of dementia" ( $p<.01)$, "Discharge date tend to be short-notice for PWD" $(p<.001)$, and "Sufficient time spent in discussing the discharge plan for intersectional collaboration of PWD" ( $p<.01)$, suggesting the differences among professionals. A statistically significant differences were evident in the following things that are considered critical upon discharging PWD: "cardinal symptoms of dementia" ( $p<.01)$, "feelings of PWD" $(p<.001)$, "feelings of PWD family" ( $p<.001)$, "feelings of healthcare professionals" $(p<.01)$, "support system for PWD family" ( $p<.05)$, and "support system for PWD" $(p<.05)$ suggesting the communication gaps among intersectoral healthcare professionals.

Communication gaps in interprofessional collaboration for hospital discharge process of PWD result in communication difficulties. Therefore, gaining an understanding of various perspectives of each profession about PWD leads to filling up the communication gaps.

\section{Acknowledgments}

The author sincerely thanks everyone who contributed to this research and publication. This study is part of research funded by a three-year (2013-2015) Grant-in-Aid for Scientific Research (Grant-in-Aid for Academic Research; Foundational Research C; Item Number: 25463369) from the Japan Society for the Promotion of Science. 


\section{References}

1) Ministry of Health, Labour and Welfare (2016) Dimentia Strategies. URL: http://www.mhlw.go.jp/stf/seisakunitsuite/bunya/0000076236.html (1, July 2016)

2) Ministry of Health, Labour and Welfare (2016) Care Manager Training Guideline 2. URL: http://www.mhlw.go.jp/file/06-Seisakujouhou-12300000-Roukenkyoku/2016.11 (12, December 2017).

3) Kinbara K, Okada S \& Shirasawa M. The structure of "role stress" in collaboration with care providers at elderly nursing care homes. Research Journal of Care and Welfare. 2012, 19 (1), 42-50.

4) Harada S \& Yamane H. Home-care workers' difficulties in providing in-home care to elderly people with mental disabilities and problems in interprofessional collaboration. Japanese Journal of Psychiatric Rehabilitation. 2013, 17 (1), 50-59.

5) Arazoe M \& Amano M. Perception of dementia by different professionals when discharging patients. Asian J Human Services. 2019, 17, 43-60.

DOI:10.14391/Ajhs.17.43

6) Matsumura A. Daijisen 2nd ed. 2012, Shogakukan, Tokyo. 1359.

7) Japan Contact Center Education and Certification Association. Contact center supervisor master manual. 2014, FOM Publishing Tokyo. 368.

8) Arazoe M. The Characteristics of Communication in Interprofessional Collaboration in Multidisciplinary Team. Asian J Human Services. 2019, 16, 29-44.

DOI:10.14391/ajhs.16.29

9) Arita E \& Mizumoto K(eds). Interprofessional healthcare implementation; team medical care theory practice and training programs. 2011, Ishiyaku Publishing, Inc., Tokyo. 61-67.

10) Hosoda M. "Team Medical Care" Utilizing for Medical and Care From Sociological Perspective Approach. 2012, Japan Nursing Association Publishing Company, Tokyo.

11) Ministry of Health, Labour and Welfare (2012) Discharge Support for Patients With Dementia. URL:http://www.mhlw.go.jp/topics/2012/01/dl/tp0118-1-40.pdf （1, July 2016).

12) Saito M \& Ito Y. Activities in Dementia Specialized Ward. Japanese Journal of Psychiatric Treatment, Seiwa Shoten Co.,Ltd., 1992, 7(10), 1097-1106.

13) Matsuoka C. Communication Skills Required for Team Approach. Case Journal of Dementia Care. 2011, 3(4), 401-408.

14) Nagashima $H$, Higashi $R$, Nagai $Y$, Murayama $H$, Watanabe $R$, Shiga $T$ et al. Result of Questionnaire Survey for Revising Healthcare Mediator Training Program Focused on Physicians. Journal of Healthcare Conflict Management. 2016, 5, 41.

15) Ministry of Health, Labour and Welfare (2007) Report of Reviewing Committee for Enhancing Basic Nursing Education.

URL: https://www.mhlw.go.jp/shingi/2007/04/dl/s0420-13.pdf (30, October 2017). 
16) Hosoda M. "Team Medical Care" Utilizing for Medical and Care From Sociological Perspective Approach. 2012, Japan Nursing Association Publishing Company, Tokyo.

17) Japanese Association of Schools of Certified Social Worker (2015) Guidelines for consultation support training. 8, 10.

URL: http://jaswe. jp/practicum/enshu_guideline 2015.pdf (10, December 2017).

18) Shinoda M. Team Management Knowledge and Skill for Better Interprofessional Collaboration. 2011, Igaku-shoin Ltd, Tokyo. 


\title{
Asian Journal of Human Services EDITORIAL BOARD
}

\author{
EDITOR-IN-CHIEF \\ Masahiro KOHZUKI Tohoku University (Japan) \\ EXECTIVE EDITORS \\ LEE, In Jae Hanshin Univerisity (Korea) \\ Satoru EBIHARA Toho University (Japan)

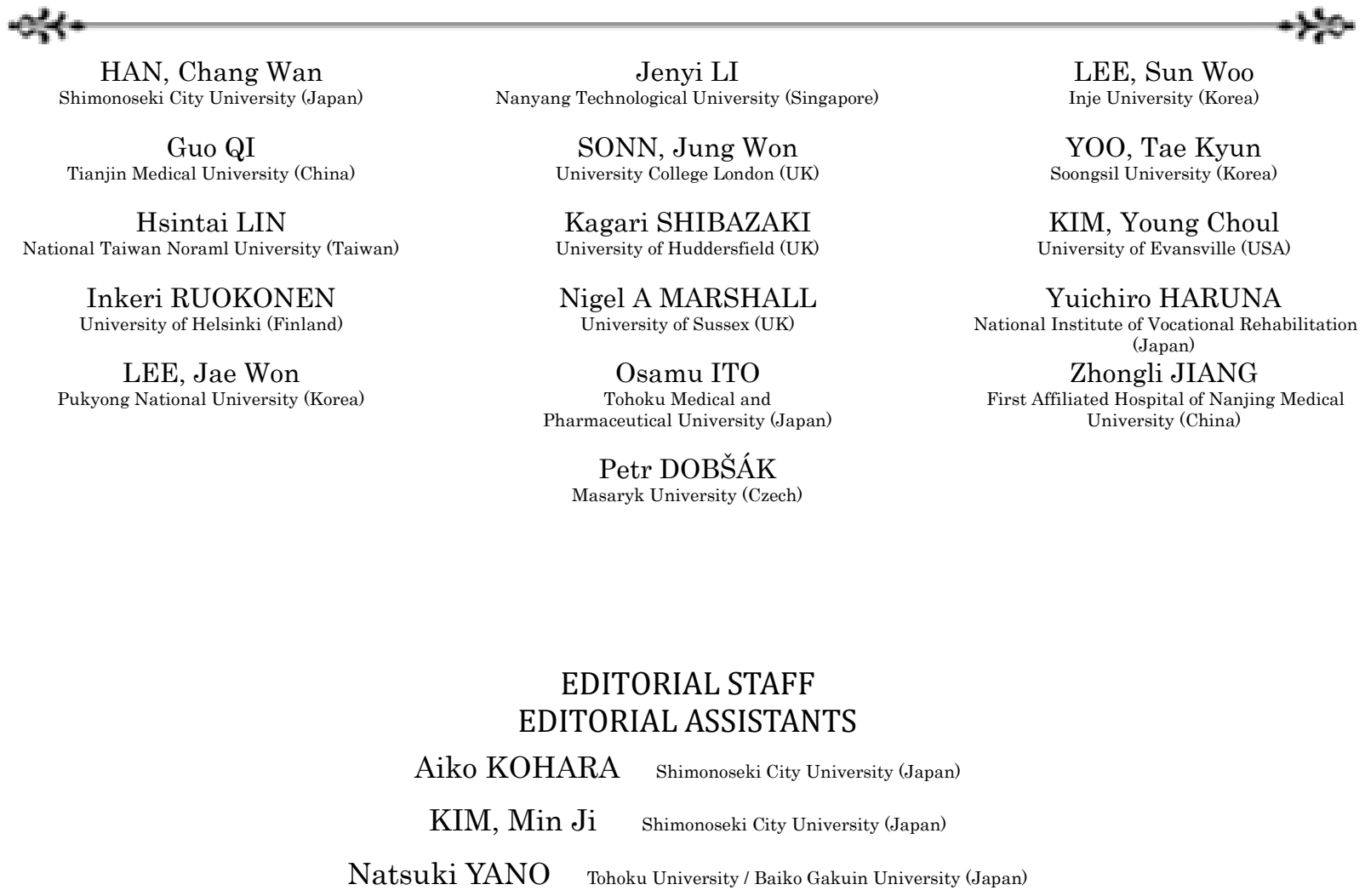

as of October 1, 2020

\section{Asian Journal of Human Services}

\section{VOL.19 October 2020}

(C) 2020 Asian Society of Human Services

\footnotetext{
Presidents | Masahiro KOHZUKI \& LEE, Sun Woo

Publisher Asian Society of Human Services

\#1Floor Ohara Bill, 2-11-5, Takezaki-Town, Shimonoseki-City, Yamaguchi-Prefecture, 750-0025, Japan E-mail: ashs201091@gmail.com

Production Asian Society of Human Services Press

\#1Floor Ohara Bill, 2-11-5, Takezaki-Town, Shimonoseki-City, Yamaguchi-Prefecture, 750-0025, Japan E-mail: ashs201091@gmail.com
} 


\section{ASIAN JOURNAL OF HUMAN SERVICES \\ VOL.19 October 2020}

\section{CONTENTS}

\section{ORIGINAL ARTICLES}

Structuring the Effects of Functional Recovery Care in a Private Home with Care Services for Older People

Advance Care Planning in Japan;

Survey of the Primary Care Physicians' View

Yuko FUJIO et al. p.1

Yumi FUKUYAMA et al. p.11

Communication Gaps in Intersectoral Healthcare Professional Collaboration for Hospital Discharge Process of Patients With Dementia

Miki ARAZOE et al. p.24

Quality of Life During Chemotherapy in Japanese Patients with Unresectable Advanced Pancreatic Cancer

Kaoru SHIBAYAMA et al. p.42

\section{SHORT PAPERS}

Examining the Relationship between Selective Mutism and Autism Spectrum Disorder

Toru SUZUKI et al. p.55

A Study of the Measures Taken by Local Governments for Care Prevention;

Examination by Questionnaire Survey

Yuji MARUYAMA p.63

\section{REVIEW ARTICLES}

Current Status of Supporting Children and Families Needing Home Health Care;

From the Viewpoint of a Coordinator

Reiko HATAKEYAMA et al. p.73

A Study on the Papers of Menstruation Scales;

The Development of a Scale for Menstrual Abnormalities

Eriko YAMAMOTO p.89

Review the Framework of Intellectual Disability from a Physiological /

Pathological Perspective in Japan

Chaeyoon CHO p.101

\section{CASE REPORT \& ACTIVITY REPORT}

A Study on the Grief Work of an Elderly Woman Who Encountered the Unexpected Death of her Spouse at Home 